\title{
Analysis of the preparation technology of a row seeder for work
}

\author{
A. Yu. Popov ${ }^{1, *}$, Noureldin Sharaby ${ }^{1,2}$, V.V. Zhurba ${ }^{1}$, and E.A. Chaika ${ }^{1}$ \\ ${ }^{1}$ Don State Technical University, pl. Gagarina 1, Rostov-on-Don, 344000, Russia. \\ ${ }^{2}$ Kafrelsheikh University, El-Geish Street, Kafr el-sheikh, 33516, Egypt. Kafr el-sheikh,.
}

\begin{abstract}
The level of preparation of a row seeder for work and its adaptability to adjustments and settings affects the efficiency of sowing. Analysis of the designs of modern row seeders shows that after-sales service remains a reserve for improving the efficiency of their use, and, therefore, increasing the agricultural crop yields. However, the technologies for the preparation and adjustment row seeders remain poorly understood, and the search for ways to reduce the complexity of maintenance for sowing units is an urgent task. The aim of the study is to build a mathematical model of the technology for checking, adjusting and tuning a row seeder on the basis of graph theory, determining a way to reduce the complexity of servicing maintenance a row seeder in preparation for sowing and justifying a rational way of organizing the seeder setting. Taking into account a number of assumptions and initial conditions, a list of operations for adjusting and setting the seeder is developed. A digraph of a row seeder preparation technology is constructed, which displays the sequence and relationship of the operations of preparation, adjusting and sitting its nodes and mechanisms. The critical path with the greatest time spent on seeder maintenance is determined. The methods for reducing the complexity of maintenance of a row seeder were established and it is recommended that further modernization of the units and mechanisms of the seeder by indicators in terms of suitability for verification, adjustment and setup. The methods of preparing the seeder for work by one performer are considered. The influence of economic factors on the number of performers during maintenance of the seeder before sowing is shown.
\end{abstract}

\section{Introduction}

The yield of row crops is determined by the quality of the field work, including the quality of sowing. Furthermore, the effectiveness of the sowing operation depends on the level of preparation of the seeder for work and its adaptability to the adjustments and settings for a given sowing crop for the required parameters and operating modes.

However, analysis of the designs of modern row seeders shows their low adaptability to testing, adjustment and setting [1]. The need for sowing in a short time and the high complexity of the preparation of the seeder lead to incomplete and poor-quality operations

\footnotetext{
* Corresponding author: popov_a_ju@mail.ru
} 
for setting the seeder to the specified sowing parameters for the cultivated crop and increased operator working time. This leads to the low efficiency of the use of a row seeder and loss of crop yield.

Improving the efficiency of use of sowing units can be achieved by reducing the complexity of service operations, increasing the adaptability of row seeders to checking and adjusting, improving and developing new technologies, methods and means of monitoring their parameters and operating modes. However, most scientific research and structural and technical improvements in the field of sowing technology are not aimed at improving maintenance, but at intensifying the processes of dosing and planting seeds in the soil. Although maintenance operations remain a reserve for increasing the efficiency of use of seeders and therefore increasing crop yields [2].

Thus, the technologies for the preparation and adjustment of row seeders remain poorly understood, and the search for ways to reduce the complexity of service maintenance of sowing units is an urgent task.

This work aims to build a mathematical model of the technology for checking, adjusting and setting the row seeder basis on graph theory, to determine ways to reduce the complexity of the maintenance of the seeder in preparation for sowing and to justify a rational way of organizing the seeder setting.

\section{Materials and methods}

The study of maintenance operations of the seeder in preparation for sowing was carried out based on technological maps for setting the sowing machines and operating instructions for operators of row seeders: Planter, MC-8, SP-8 Gaspardo, Great Plains, Amazone and other seeders [3]. During the analysis of this material, operations for checking, adjusting and setting up row seeders were identified, generalized and structured, and the time spent on their implementation was determined. Then, using the theory of graphs, a mathematical model of the technology for preparing the seeder for sowing was constructed in the form of a directed graph that determines the sequence and relationship of operations [4].

In this case, the following assumptions and initial conditions are accepted. A sectional type pneumatic seeder with installed vertical-disk vacuum type sowing devices and the use of a mechanical sowing device for excess seeds is considered [5]. maintenance of the Seeder is carried out on a special site with a flat hard surface. The seeder is fully equipped with working bodies, units and mechanisms. Checking and adjustment are carried out using special tools and measuring instruments in accordance with agricultural requirements. The seeder frame must be intact and without distortions, with high-quality welds. The fastening of units and mechanisms must be reliable. Foreign objects are not allowed in grain and fertilizer hoppers. All bearing assemblies and friction surfaces are lubricated.

If these conditions are not met, the seeder must be sent for repair. In case of detection of defective parts, units and mechanisms, they are replaced with new or repaired.

When building a model, repeated adjusting operations of the same type of units and mechanisms are considered as one vertex of the graph. For example, the eight-section seeder ejector adjustment contains 8 operations of the same name for adjusting each sowing unit of the sowing sections.

Further, according to the directed graph, the path with the greatest expenditure of time is determined, which is critical in the preparation of row seeder to work.

Determining the critical path in the technology of seeder preparation will reveal the reserves for reducing the complexity of maintenance of the sowing unit, the possibility of reducing the number of service operations, as well as justify the possible modernization of the units and mechanisms of the seeder to increase its adaptability to adjustments and settings. 


\section{Results and discussion}

As a result of the analysis of technological maps for setting up and operating instructions for a number of modern row seeders of the sectional type, a list of verification operations, settings and adjustments has been compiled, as presented in table 1.

Table 1. List of operations performed when preparing a row seeder for operation

\begin{tabular}{|c|c|c|c|c|c|}
\hline № & Type, name of work (operations) & Symbols & $\begin{array}{l}\text { Work } \\
\text { number }\end{array}$ & $\begin{array}{l}\text { Based on } \\
\text { the work, } \\
\text { number }\end{array}$ & $\begin{array}{l}\text { Duration of } \\
\text { work, h }\end{array}$ \\
\hline 1 & 2 & 3 & 4 & 5 & 6 \\
\hline 1 & $\begin{array}{l}\text { Delivery and installation of the seeder } \\
\text { at the adjustment platform }\end{array}$ & $\mathrm{a}_{1}$ & 1 & 0 & 0,057 \\
\hline 2 & $\begin{array}{l}\text { Checking the horizontal position of the } \\
\text { seeder frame }\end{array}$ & $\mathrm{a}_{2}$ & 2 & 1 & 0,018 \\
\hline 3 & Check tire pressure & $a_{3}$ & 3 & 1 & 0,008 \\
\hline 4 & Check coulters placement & $\mathrm{a}_{4}$ & 4 & 1 & 0,025 \\
\hline 5 & $\begin{array}{l}\text { Checking the correct installation of } \\
\text { sprockets and chain tension }\end{array}$ & a6 & 5 & 1 & 0,034 \\
\hline 6 & $\begin{array}{l}\text { Checking clearances in fertilizer } \\
\text { distributing units }\end{array}$ & $a_{5}$ & 6 & 1 & 0,055 \\
\hline 7 & $\begin{array}{l}\text { Adjusting the horizontal position of the } \\
\text { seeder frame }\end{array}$ & $a_{7}$ & 7 & 2 & 0,071 \\
\hline 8 & Setting the required tire pressure & $a_{8}$ & 8 & 3 & 0,080 \\
\hline 9 & $\begin{array}{l}\text { Adjustment of preload on springs of } \\
\text { pushrods and sowing sections }\end{array}$ & $\mathrm{a}_{9}$ & 9 & 16 & 0,106 \\
\hline 10 & coulters placement & $a_{10}$ & 10 & 4 & 0,110 \\
\hline 11 & Adjusting the vacuum & $a_{11}$ & 11 & 1 & 0,015 \\
\hline 12 & Adjustment of sowing devices & $\mathrm{a}_{12}$ & 12 & 18 & 0,224 \\
\hline 13 & $\begin{array}{l}\text { Adjusting the sprocket setting and chain } \\
\text { tension }\end{array}$ & $\mathrm{a}_{14}$ & 13 & 5 & 0,062 \\
\hline 14 & Gap adjustment in fertilizer units & $a_{13}$ & 14 & 6 & 0,049 \\
\hline 15 & $\begin{array}{l}\text { Setting the position of the seeder frame } \\
\text { in a horizontal plane }\end{array}$ & $a_{15}$ & 15 & 7 & 0,067 \\
\hline 16 & Setting the depth of the Coulter stroke & $a_{16}$ & 16 & 8 & 0,072 \\
\hline 17 & $\begin{array}{l}\text { Installation of preloading springs of } \\
\text { pushrods and sowing sections }\end{array}$ & $a_{17}$ & 17 & 9 & 0,058 \\
\hline 18 & Setting the required vacuum & $a_{18}$ & 18 & 11 & 0,018 \\
\hline 19 & $\begin{array}{l}\text { Setting the position of the sowing } \\
\text { devices }\end{array}$ & $a_{19}$ & 19 & 12 & 0,055 \\
\hline 20 & Setting the seeding rate & $a_{21}$ & 20 & 13 & 0,152 \\
\hline 21 & Setting the fertilizer application rate & $a_{20}$ & 21 & 13,14 & 0,097 \\
\hline 22 & $\begin{array}{l}\text { Removing the seeder from the levelling } \\
\text { platform }\end{array}$ & a 22 & 22 & $\begin{array}{c}10,15,17 \\
19-21\end{array}$ & 0,027 \\
\hline
\end{tabular}

To this case, the operation 20 for setting the seeding rate includes the following works: determination of gear numbers and gear ratios of the gear mechanism in accordance with the seeding rate of a given crop; installation a seeding disc with a certain number and size of holes and a corresponding gear ratio of the transmission mechanism; setting the desired gear ratio using the gear mechanism.

Operation 21 to set the fertilizer flow rate includes the following work: determining the gear ratio of the gear mechanism in accordance with a predetermined rate of mineral fertilizer application; setting the required gear ratio by replacing the drive sprockets and gears of the fertilizer distributing mechanism. 
In accordance with table 1, a mathematical model of the technology for preparing the seeder for work is built in the form of a directed graph, shown in figure 1.

Events are presented in the form of the vertices of this digraph, where the numbers indicate the event numbers from the first column of the list of work performed. Arcs of a digraph denote work, and the numbers above them indicate the designation and duration of operations. The event marked with zero is the initial state of the seeder, and the number 22 is the target state of the seeder. Works that cannot be carried out without performing the following operations are indicated by dashed arcs.

The Roman numerals on the digraph (figure 1) denote blocks of different seeder states: I - the initial state of the seeder before preparing for work; II - seeder delivered and installed on a special platform; III - the seeder tested; IV - the seeder adjusted; V - the seeder is prepared for work; VI - seeder is removed from the site, the work is completed.

It should be noted that when compiling a list of operations and building a digraph, one performer was taken into account.

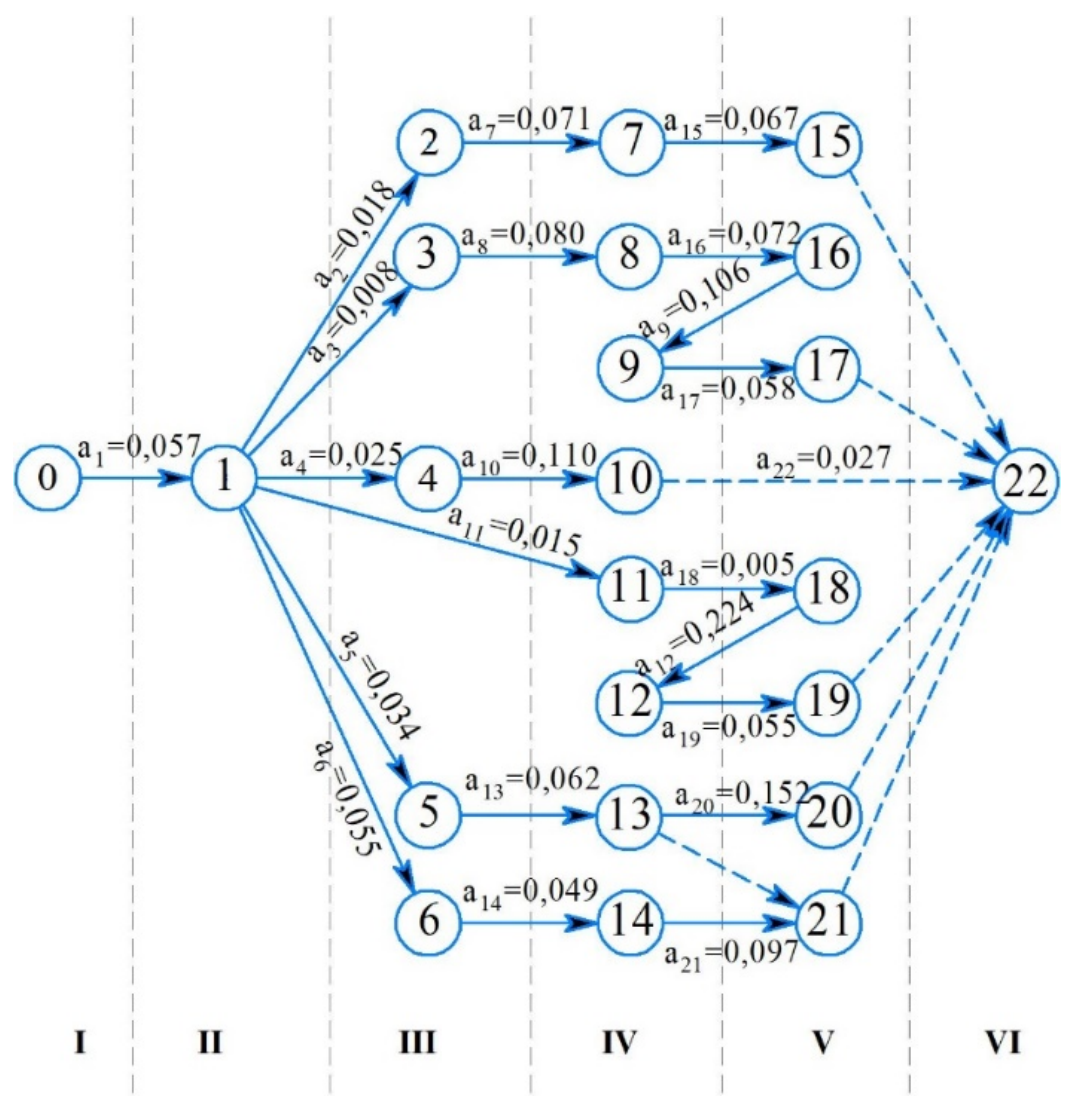

Fig. 1. A digraph of the technology for preparing a row seeder for work

Consider a digraph and determine the critical path with the greatest time spent on preparing the seeder for work. This will determine the possibilities of reallocating resources to reduce the total time for preparing the seeder. Also, the critical path and paths close to it determine the direction of the necessary modernization and improvement of the units and mechanisms of the seeder in terms of fitness for verification, adjustment and setting. To do this, we will make a list of all digraph paths and determine the time to complete the work for each of them. 


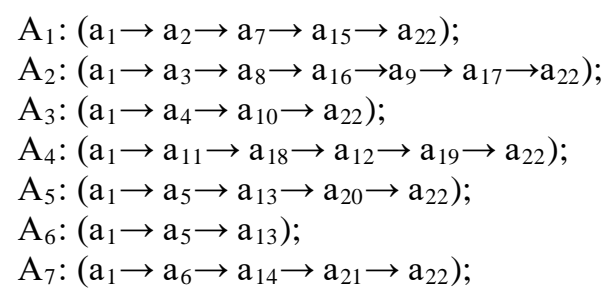

$$
\begin{aligned}
& \mathrm{T}_{1}=\mathrm{t}_{1}+\left(\mathrm{t}_{2}+\mathrm{t}_{7}+\mathrm{t}_{15}\right)+\mathrm{t}_{22}=0,240 \mathrm{~h} . \\
& \mathrm{T}_{2}=\mathrm{t}_{1}+\left(\mathrm{t}_{3}+\mathrm{t}_{8}+\mathrm{t}_{16}+\mathrm{t}_{9}+\mathrm{t}_{17}\right)+\mathrm{t}_{22}=0,408 \mathrm{~h} . \\
& \mathrm{T}_{3}=\mathrm{t}_{1}+\left(\mathrm{t}_{4}+\mathrm{t}_{10}\right)+\mathrm{t}_{22}=0,219 \mathrm{~h} . \\
& \mathrm{T}_{4}=\mathrm{t}_{1}+\left(\mathrm{t}_{11}+\mathrm{t}_{18}+\mathrm{t}_{12}+\mathrm{t}_{19}\right)+\mathrm{t}_{22}=0,383 \mathrm{~h} . \\
& \mathrm{T}_{5}=\mathrm{t}_{1}+\left(\mathrm{t}_{5}+\mathrm{t}_{13}+\mathrm{t}_{20}\right)+\mathrm{t}_{22}=0,332 \mathrm{~h} . \\
& \mathrm{T}_{6}=\mathrm{t}_{1}+\left(\mathrm{t}_{5}+\mathrm{t}_{13}\right)=0,153 \mathrm{~h} . \\
& \mathrm{T}_{7}=\mathrm{t}_{1}+\left(\mathrm{t}_{6}+\mathrm{t}_{14}+\mathrm{t}_{21}\right)+\mathrm{t}_{22}=0,285 \mathrm{~h} .
\end{aligned}
$$

Then we define in the digraph the full paths representing sequences of operations in which each subsequent work cannot begin without completing the previous one. If the operation will depend on several previous works, as is seen in the case of operation 21 of setting the fertilizer application rate, then the full path with the longest execution time is selected. this path will be the main one, and all the others will be secondary. In this case, the work of some main paths is carried out simultaneously and independently of the work corresponding to other full paths.

Thus, the list of main full paths and their time to complete the work will be as follows:

$$
\begin{array}{ll}
\mathrm{A}^{0}{ }_{1}:\left(\mathrm{a}_{1} \rightarrow \mathrm{a}_{2} \rightarrow \mathrm{a}_{7} \rightarrow \mathrm{a}_{15} \rightarrow \mathrm{a}_{22}\right) ; & \mathrm{T}_{1}=0,240 \mathrm{ч} . \\
\mathrm{A}^{0}{ }_{2}:\left(\mathrm{a}_{1} \rightarrow \mathrm{a}_{3} \rightarrow \mathrm{a}_{8} \rightarrow \mathrm{a}_{16} \rightarrow \mathrm{a}_{9} \rightarrow \mathrm{a}_{17} \rightarrow \mathrm{a}_{22}\right) ; & \mathrm{T}_{2}=0,408 \mathrm{~h} . \\
\mathrm{A}^{0}{ }_{3}:\left(\mathrm{a}_{1} \rightarrow \mathrm{a}_{4} \rightarrow \mathrm{a}_{10} \rightarrow \mathrm{a}_{22}\right) ; & \mathrm{T}_{3}=0,219 \mathrm{~h} . \\
\mathrm{A}^{0}{ }_{4}:\left(\mathrm{a}_{1} \rightarrow \mathrm{a}_{11} \rightarrow \mathrm{a}_{18} \rightarrow \mathrm{a}_{12} \rightarrow \mathrm{a}_{19} \rightarrow \mathrm{a}_{22}\right) ; & \mathrm{T}_{4}=0,383 \mathrm{~h} . \\
\mathrm{A}^{0}{ }_{5}:\left(\mathrm{a}_{1} \rightarrow \mathrm{a}_{5} \rightarrow \mathrm{a}_{13} \rightarrow \mathrm{a}_{20} \rightarrow \mathrm{a}_{22}\right) ; & \mathrm{T}_{5}=0,332 \mathrm{~h} . \\
\mathrm{A}^{0}{ }_{6}:\left(\mathrm{a}_{1} \rightarrow \mathrm{a}_{6} \rightarrow \mathrm{a}_{14} \rightarrow \mathrm{a}_{21} \rightarrow \mathrm{a}_{22}\right) ; & \mathrm{T}_{6}=0,285 \mathrm{~h} .
\end{array}
$$

The greatest time consumption $\mathrm{T}_{2}=0,408 \mathrm{~h}$ will occur on the way to adjust the depth of coulters stroke $\mathrm{A}^{0}{ }_{2}$, which is considered critical. On the other branches of the digraph, there are time reserves from $0,168 \mathrm{~h}$ on $\mathrm{A}^{0}{ }_{3}$ to $0.025 \mathrm{~h}$ on $\mathrm{A}^{0}{ }_{4}$. It is also possible to note the path to adjust the ejector of the extra seeds of the sowing apparatus $\mathrm{A}^{0}{ }_{4}\left(\mathrm{~T}_{4}=0,383 \mathrm{~h}\right)$, as close to critical. Thus, in order to increase the efficiency of use and reduce the labor intensity of maintenance of a section-type row seeder, it is first necessary to modernize the mechanisms for regulating the depth of the coulter stroke and devices that determine the quality indicators of dosing of the sowing devices, in particular, dropper of excess seeds.

The average completion time for all work is determined by the formula:

$$
T_{c p}=\frac{1}{n} \sum_{i=1}^{n} T_{i}
$$

where $n$ is the number of main paths, in our case $n=6$.

That is, for the case under consideration, the average time for preparing the seeder for sowing will be $T_{c p}=0,311 \mathrm{~h}$. But formula (1) does not take into account the number of performers, their qualifications, and the availability of tools for monitoring and diagnostics.

It is known that one performer can adjust the seeder in two ways [2, 3]. The first method is to prepare the seeder by type of work. First, only a check of all the units of the seeder is carried out, then their adjustment and finally tuning to the specified parameters and operating modes. In this case, the total preparation time of the seeder by type of work $T_{1}$ is determined by the formula

$$
T_{1}=\sum_{i=1}^{n}\left(T_{o}+T_{c 1}+T_{t 1}\right)+\sum_{i=1}^{n} T_{m},
$$

where $T_{o}$ - is the main execution time of the i-th operation, h;

$T_{c 1}$ - time to change the tool when changing the type of work, h;

$T_{t 1}$ - time to change the place of work, h;

$T_{m}$ - time to the mark nodes that do not meet the requirements, h; 
$n$ - is the total number of checks, adjustments and settings of the seeder;

The second method is to prepare the seeder according to the units and mechanisms of the seeder. That is, checking, adjustment and setting up one mechanism, then another and so on.

At the same time, the total preparation time of the seeder by units and mechanisms $T_{2}$ is determined by the formula

$$
T_{2}=\sum_{i=1}^{n}\left(T_{o}+T_{c 2}+T_{t 2}\right),
$$

where $T_{c 2}$ - is the time to change the tool when changing the type of work, h;

$T_{t 2}$ - time of transition from one mechanism to another, h;

From formulas (2) and (3) it can be seen that the main time $T_{o}$ is the same in both methods. But the time of transition from one workplace to another, the time to change tools will differ. Also, when performing the first method, it is necessary to carry out an additional operation of marking nodes for compliance with agrotechnical requirements.

In addition, when preparing the seeder by type of work, it is necessary to change the tool and the working position in each operation. And when preparing for the units and mechanisms, this should be done. Only when changing the unit or mechanism. Thus, the preparation of the seeder by units and mechanisms takes less time than by type of work. Therefore, in the case of one performer, it is recommended to prepare the seeder using the second way. For example, one of the possible routes for a digraph could be (figure 1).

$$
\mathrm{a}_{0} \rightarrow \mathrm{a}_{1} \rightarrow \mathrm{a}_{2} \rightarrow \mathrm{a}_{7} \rightarrow \mathrm{a}_{15} \rightarrow \mathrm{a}_{3} \rightarrow \mathrm{a}_{8} \rightarrow \mathrm{a}_{16} \rightarrow \mathrm{a}_{9} \rightarrow \mathrm{a}_{17} \rightarrow \mathrm{a}_{4} \rightarrow \mathrm{a}_{10} \rightarrow \mathrm{a}_{11} \rightarrow \mathrm{a}_{18} \rightarrow \mathrm{a}_{12} \rightarrow \mathrm{a}_{19} \rightarrow
$$
$\mathrm{a}_{5} \rightarrow \mathrm{a}_{13} \rightarrow \mathrm{a}_{20} \rightarrow \mathrm{a}_{6} \rightarrow \mathrm{a}_{14} \rightarrow \mathrm{a}_{21} \rightarrow \mathrm{a}_{22}$.

At the same time, given the duration of the work (table 1), the total execution time of all operations will be $1,46 \mathrm{~h}$.

In the case of an increase in the number of performers, the total time spent on preparing the seeder is divided equally for each participant. At the same time, the more performers involved, the less time and operations will be per person. And with a certain limit number of performers, there may be a situation where each employee will perform one operation without changing the tool and his working position. In this case, the total time of preparation of the seeder in both ways will be equal to:

$$
T_{1}=T_{2} \text { at } k \rightarrow k_{n},
$$

where $k$ - is the number of performers;

$k_{n}$ - the maximum number of performers.

However, the number of performers will be limited by economic factors and determined from the analysis of the objective function $\mathrm{Z}$ to a minimum [2]:

$$
Z=L+P \rightarrow \min ,
$$

where $L$ - losses from product shortages, rub.;

$P$ - the cost of preparing the seeder for work and its changeover, rub.

\section{Conclusions}

As a result of the study, a mathematical model of a generalized technology for preparing a row seeder for work is constructed in the form of a digraph, which reflects the sequence and interconnection of the operations of preparation, adjustment and setting of its units and mechanisms.

The ways to reduce the labor intensity of maintenance of a row seeder are defined. In particular, to increase the efficiency of using modern seeders, it is necessary first of all to modernize the mechanisms for regulating the depth of the coulter stroke, as well as the 
devices that regulate the quality of dosing of the sowing devices, in particular, the droppers of excess seeds.

It was found that the labor intensity of preparing the seeder for work on units and mechanisms is less than when preparing according to the type of work. The influence of economic factors on the number of performers during maintenance of the seeder before sowing is presented, taking into account losses from product shortages due to lengthening the sowing time and the cost of preparing and readjustment of the seeder.

\section{References}

1. B. A. Stout, B. Cheze, CIGR Handbook of Agricultural Engineering, Volume III Plant Production Engineering. (American Society of Agricultural Engineers, 1999).

2. M.P. Tishaninov, N.G. Malmin, Preparation of grain seeders for work, Mechanization and electrification of agriculture, №3. pp. 7-9 (1991).

3. N.P. Tishaninov, E.A. Tseboev, A.F. Voloboev, Technological maps for setting up and adjusting the main tillage and sowing agricultural machines: recommendations for machine operators and farm specialists (Tambov, 1989).

4. R.J. Wilson, Introduction to Graph Theory (Longman Group Ltd, 1979).

5. A. Yu. Popov, D.K. Muratov, Study of the sealing elements impact on air flow distribution in a seed vessel of seeding mechanism, MATEC Web Conferences, Vol. 224, 05055 (2018). DOI: https://doi.org/10.1051/matecconf/201822405015. 